\title{
EVALUATION OF THE DOSE LEVELS IN THE IRRADIATION CHANNELS OF PU-BE NEUTRON SOURCES STORAGE DEVICE BY USING NEUTRON ACTIVATION ANALYSIS AND MCNP6 MODELLING
}

\author{
E. Lagzdina, R. Plukienė, D. Lingis, J. Garankin, A. Plukis, D. Germanas and \\ V. Remeikis
}

Center for Physical Sciences and Technology, Savanorių pr. 231, LT-02300 Vilnius, Lithuania

rita.plukiene@,ftmc.lt

\begin{abstract}
PuBe neutrons sources of Educational Neutron Laboratory in the Center for Physical Sciences and Technology are used in several activities including neutron activation for educational purposes and laboratory irradiation experiments. In this work we address the dose rate estimation in the irradiation channels of reconstructed $\mathrm{PuBe}$ neutron sources storage device in the particular positions dedicated for neutron irradiation experiments using neutron activation analysis (NAA) and MCNP6 modelling. The results on neutron activation of $\mathrm{V}_{2} \mathrm{O}_{5}, \mathrm{MnO}_{2}, \mathrm{Al}$ and $\mathrm{Na}_{2} \mathrm{CO}_{3}$ were analyzed and compared with MCNP6 model prediction results. The conclusions on the actual neutron flux energy distribution and model corrections are drawn. The absolute neutron intensity at dedicated irradiation points as well as neutron and gamma dose rates are obtained.
\end{abstract}

KEYWORDS: PuBe neutron source, neutron activation analysis, MCNP6 modeling

\section{INTRODUCTION}

Alpha-neutron sources produce neutrons through the $(\alpha, \mathrm{n})$ reaction: ${ }^{9} \mathrm{Be}+\alpha \rightarrow{ }^{13 *} \mathrm{C} \rightarrow \mathrm{n}+{ }^{12} \mathrm{C}$; $\rightarrow{ }^{8} \mathrm{Be}+\mathrm{n}+\alpha ; \rightarrow \mathrm{n}+3 \alpha$. The Q-value of this reaction is $5.7 \mathrm{MeV}$ that is shared among the reaction products. The intermediate state of this reaction is the formation of the compound nucleus of ${ }^{13} \mathrm{C}$, and neutrons are produced through different channels.

In the Educational Neutron Laboratory (ENL) at the Center for Physical Sciences and Technology (CPST) the neutrons are produced by $4 \mathrm{PuBe}$ neutron sources $\left(2{ }^{239} \mathrm{PuBe}\right.$ and $\left.2{ }^{238} \mathrm{PuBe}\right)$ all together are of $4.5 \cdot 10^{7} \mathrm{n} / \mathrm{s}$ of total activity according to existing documents. They are used mainly for educational purposes. They are situated in the neutron storage device (container filled by polyethylene) on the first floor of the building which construction initially was designed to work with various kinds of radiation. In the neutron laboratory the student practical works of specimen irradiation, life time experiments, coincidence experiments and other are performed. The aim of this work was to estimate the neutron flux intensity and energy distribution in the particular positions dedicated for neutron activation/irradiation experiments. The knowledge of physical features of neutron source is important for planning of the experiments and for estimation of laboratory conditions: safety and radiation protection. 
Neutron activation analysis (NAA) and MCNP6 modeling was used for identification of neutron flux parameters such as neutron flux intensity and energy distribution similarly as in [1]. The samples were irradiated at different positions and by measuring $\gamma$ spectra the neutron flux intensity was identified. Peculiar elements with established neutron capture cross sections $-\mathrm{V}_{2} \mathrm{O}_{5}+\mathrm{KNO}_{3}, \mathrm{MnO}_{2}+\mathrm{KNO}_{3}, \mathrm{Al}$ and $\mathrm{Na}_{2} \mathrm{CO}_{3}+\mathrm{KNO}_{3}$ have been measured for neutron activation analysis to cover the all (activation) neutron energy diapason from thermal to fast neutron.

\section{NUMERICAL MODELING}

For neutron flux and energy distribution assessment we have used MCNP6 code [2] and ENDF-VII [3] cross-section libraries. The simultaneous coupled neutron-gamma transport calculations were used. MCNP6 has been used for neutron transport calculation, energy deposition and assessment of the reaction rates in the sample. The nuclear interaction $(\mathrm{n}, \gamma),(\mathrm{n}, \mathrm{p})$ or $(\mathrm{n}, \alpha)$ reaction rates $(R R)$ can be defined with the classic Fredholm equation of the first order [2]:

$$
R R_{i}=N \int_{0}^{\infty} \sigma(E) \phi(r, E) d E
$$

were,

$R R_{i}$ - rate at which reactions are occurring in the nuclide $i$ (reactions $/ \mathrm{s}$ ); $N$ - number of target atoms in the sample; $\sigma(E)$ - energy-dependent microscopic cross-section; $\phi(E)$ - energy-dependent neutron flux in the sample $\left(\mathrm{n} / \mathrm{cm}^{2} \mathrm{~s}\right)$. After solving the integral equation (1) by performing energy group discretization procedure for neutron flux and microscopic cross-section calculation in MCNP6 we obtain the average macroscopic values of $\sigma$ and $\phi$ in the sample and nuclide $i$ production rate:

$$
R R_{i}=N \sigma \phi
$$

Nuclide production reaction rate further is used to obtain daughter nuclide $\left(N_{d}\right)$ number after target nuclide $(N)$ irradiation in the neutron flux:

$$
N \stackrel{R R_{i}}{\longrightarrow} N_{d} \stackrel{\lambda N_{d}}{\longrightarrow} N_{s}
$$

$N_{d}$ is a function of the production and loss rates $\left(\lambda N_{d}\right)$

$$
\frac{d N_{d}}{d t}=N \sigma \phi-\lambda N_{d}
$$

were $\lambda$ - decay constant for the daughter nuclide; $\lambda=0,693 / \mathrm{T}_{1 / 2}, \mathrm{~T}_{1 / 2}$ is the half-life of the reaction.

If the initial concentration of the daughter nuclide $N_{d}$ is 0 at $\mathrm{t}=0$, then the solution of (4) for the number of daughter nuclides present during the irradiation is:

$$
N_{d}(t)=\frac{N \sigma \phi}{\lambda}\left(1-e^{-\lambda t}\right)
$$

The activity $A$ of the sample is given by $\lambda N$. Hence, the activity $(A)$ at the end of the irradiation $\left(t_{i}\right)$ will be:

$$
A=N \sigma \phi\left(1-e^{-\lambda t_{i}}\right)
$$

$1-e^{-\lambda t_{i}}=S$ is called the saturation factor, it means what the induced activity approaches a horizontal asymptote or saturated activity $\left(\mathrm{A}_{\infty}\right)$ for an infinitely long irradiation time. The $\left(A_{\infty}\right)$ activity is obtained from (4): $A_{\infty}=N \sigma \phi=\lambda N_{d}$ and if the irradiation has proceeded for a time $\mathrm{t}_{\mathrm{i}}$ at which time the sample is removed with an activity $A$ :

$$
A_{\infty}=\frac{A}{\left(1-e^{-\lambda t_{i}}\right)}
$$

The reaction rates and the corresponding saturation activity were calculated for the neutron activation samples at different locations (different channels and different heights). 
The simplified scheme of the neutron sources storage container at the neutron laboratory of CPST is presented in Fig. 1. The neutron source storage container is the cylindrical well $0.6 \mathrm{~m}$ of diameter, 1.8 $\mathrm{m}$ of depth under the ground, which is filled by paraffin matrix as moderator. The neutron sources are placed in central channel of the well and two vertical experimental channels are situated $15 \mathrm{~cm}$ and 20 $\mathrm{cm}$ from the source to obtain different neutron flux characteristics during irradiation experiments.

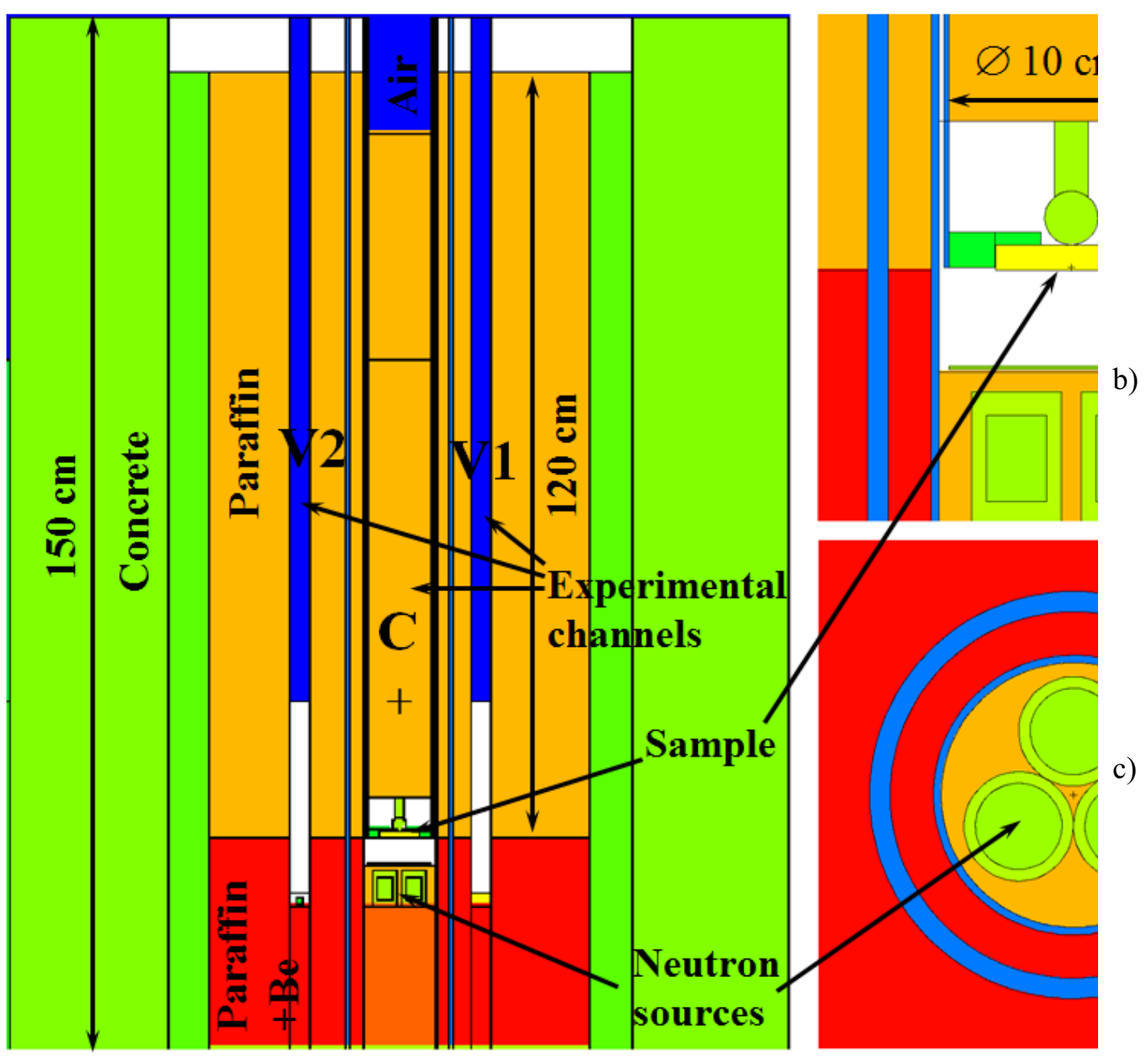

a)

Figure 1. (a) The simplified scheme of the neutron sources container under the ground; (b) vertical view of the central irradiation channel with sample place dedicated for the cells saturated with $B$ irradiation; (c) arrangement of PuBe neutron sources horizontal cut of the central experimental channel.

Calculated neutron flux in the experimental channels of neutron well is presented in Fig. 2. Both V2 and $\mathrm{V} 1$ are thermal neutron channels with different thermal neutron contribution correspondingly $76 \%$ and $70 \%$ with different intensity of the neutron flux as it is observed in Fig. 2. 


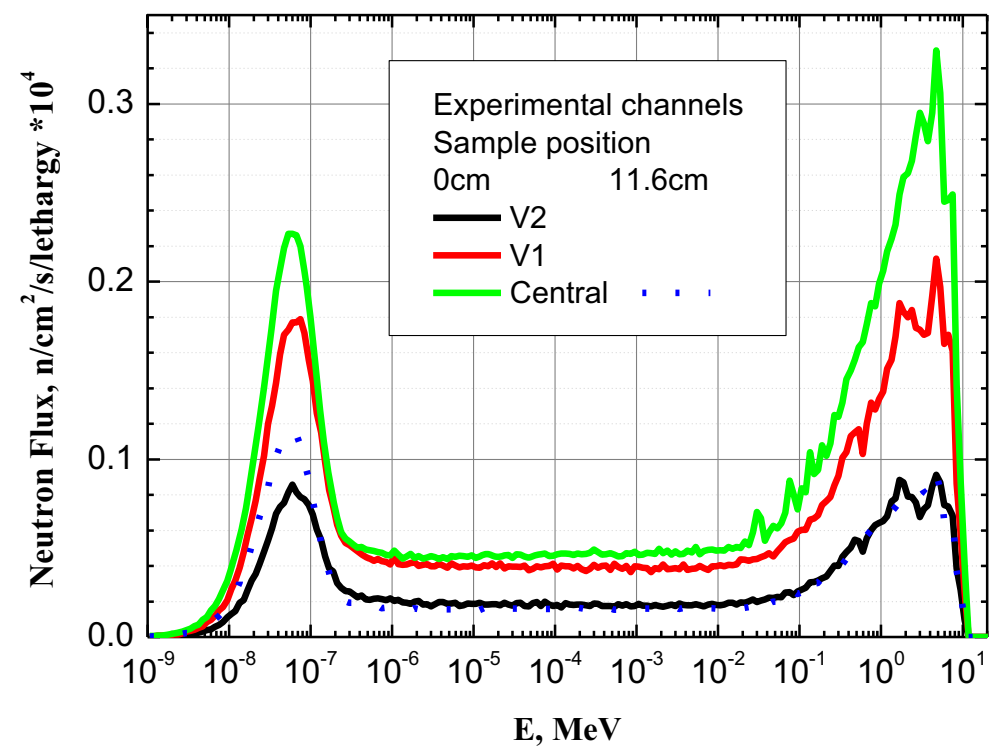

Figure 2. Neutron flux spectra in the experimental channels of neutron well.

\section{NEUTRON ACTIVATION ANALYSIS}

If the quantitative and nuclear properties of the activated element in the sample are known the neutron flux $\phi\left(\mathrm{n} / \mathrm{cm}^{2} / \mathrm{s}\right)$, can be obtained from (6) equation [5]:

$$
\phi=\frac{A \cdot w}{\sigma \cdot m \cdot N_{A} \cdot \alpha \cdot S}
$$

where: $A$ is activity of the element in the sample at the end of irradiation $(\mathrm{Bq}), \sigma-$ reaction cross section $\left(\mathrm{cm}^{2}\right), m$ - mass of the target element $(\mathrm{g}), \mathrm{N}_{\mathrm{A}}-$ Avogadro's number ( $6.023 \times 10^{23}$ molecules $\left./ \mathrm{mole}\right), \alpha-$ fraction of the target isotope in the sample; $S=1-e^{-\lambda t_{i}}-$ saturation factor, $w$-atomic weight of the element.

The activity of the isotope can be obtained from the counts in the total absorption peak in the gamma spectrum of the sample registered using the high purity germanium (HPGe) detector [6]. The spectrum of the gamma radiation is accumulated for a time $\Delta t$, long enough to get reasonable statistics under the total absorption peak. The time is usually at least one half-life. The measured activity $\left(A_{m}\right)$ can be determined from the following equation:

$$
A_{m}=\frac{\Sigma_{p} / \Delta t-\Sigma_{b} / \Delta t}{\eta \cdot \varepsilon_{t}}
$$

Where: $\Sigma$ is sum of the counts under the total absorption peak, $\Sigma_{b}$ is background for the same counting period $\Delta t, \eta$ is the gamma transition yield; $\varepsilon_{t}$ - absolute efficiency of registration in the detector (this value is obtained from the detector calibration curve at the energy of $\gamma$ emitted by the sample see equation (12)), which was adjusted taking into account the MCNP modeling of detector registration for each sample geometry including the self absorption, distance, gamma ray coincidence effects, etc.).

The sample activity also decreases due to radioactive decay during the measurement time $\Delta t$ and it should be taken into account:

$$
A_{0}=\frac{A_{m} \Delta t}{\left(1-e^{-\lambda \Delta t}\right)}
$$


The sample activity at the beginning of the measurement $\left(A_{0}\right)$ :

$$
A_{0}=A \cdot e^{-\lambda t_{d}},
$$

where $t_{d}$ is delay time between stop of irradiation and beginning of the measurement.

From these two equations we can obtain the activity of the sample $A$ after irradiation:

$$
A=\frac{A_{m} \Delta t \cdot e^{\cdot \lambda t_{d}}}{\left(1-e^{-\lambda \Delta t}\right)}
$$

This calculated activity was used for calculation of the neutron flux (see 8) in the irradiation channels at certain positions. The value of the corresponding saturation activity calculated using MCNP6.

According to the experimental neutron activation results the certain adjustment of parameters of neutron source intensity has been performed for exact neutron source representation.

\section{EXPERIMENTAL EQUIPMENT}

Gamma-ray spectrometric measurements of the neutron-activated samples were carried out using HPGe detector coupled to the MCA Canberra DSA1000 with Genie-2000 gamma ray spectroscopy analysis software (Canberra Industries, USA). The HPGe detector was of GC2520 series by Canberra, USA, with relative efficiency of $25 \%$, and energy resolution of $1,1 \mathrm{keV}$ at $121.78 \mathrm{keV}\left({ }^{152} \mathrm{Eu}\right)$ and at $2 \mathrm{keV}$ at $1332.5 \mathrm{keV}\left({ }^{60} \mathrm{Co}\right)$. Absolute detector efficiency has been calibrated for the each neutron activation sample (Al, V, Mn, Na) geometry using MCNP6 modeling technique. The known ${ }^{40} \mathrm{~K}$ concentration was used for estimation of absolute detector efficiency calibration and similar matrix - selfabsorption - effects. The HPGe detector registration efficiency factors for each of the neutron activation products in the $661-2754 \mathrm{keV}$ energy range are presented in Fig. 3.

Table I. Radioactive decay energies, transition probabilities and half lives of gamma nuclides measured used in the neutron activation and detector calibration experiments.

\begin{tabular}{|c|c|c|c|}
\hline Gamma ray transition & $\mathrm{E}(\mathrm{keV})$ & $\mathrm{T}_{1 / 2}$ & Probability (\%) \\
\hline${ }^{137} \mathrm{Cs}(\beta-) \gamma \rightarrow{ }^{137} \mathrm{Ba}$ & 661.657 & $30.07 \mathrm{y}$ & 85 \\
\hline${ }^{27} \mathrm{Mg}(\beta-) \gamma \rightarrow{ }^{27} \mathrm{Al}$ & 843 & $9.458 \mathrm{~min}$ & 71.8 \\
\hline${ }^{56} \mathrm{Mn}(\beta+) \gamma \rightarrow{ }^{56} \mathrm{Fe}$ & 846.7638 & $2.578 \mathrm{~h}$ & 98.85 \\
\hline${ }^{27} \mathrm{Mg}(\beta-) \gamma \rightarrow{ }^{27} \mathrm{Al}$ & 1085.837 & $9.458 \mathrm{~min}$ & 28 \\
\hline${ }^{60} \mathrm{Co}(\beta+) \gamma \rightarrow{ }^{60} \mathrm{Ni}$ & 1173.228 & $1925.1 \mathrm{~d}$ & 100 \\
\hline${ }^{60} \mathrm{Co}(\beta+) \gamma \rightarrow{ }^{60} \mathrm{Ni}$ & 1332.492 & $1925.1 \mathrm{~d}$ & 100 \\
\hline${ }^{24} \mathrm{Na}(\beta-) \gamma \rightarrow{ }^{24} \mathrm{Mg}$ & 1368.626 & $14.959 \mathrm{~h}$ & 98.90 \\
\hline${ }^{52} \mathrm{~V}(\beta-) \gamma \rightarrow{ }^{52} \mathrm{Cr}$ & 1434 & $3.743 \mathrm{~min}$ & 20.7 \\
\hline${ }^{40} \mathrm{~K}(\beta-) \gamma \rightarrow{ }^{40} \mathrm{Ca}$ & 1460.83 & $1.277 \times 10^{9} \mathrm{y}$ & 11 \\
\hline${ }^{42} \mathrm{~K}(\beta-) \gamma \rightarrow{ }^{42} \mathrm{Ca}$ & 1524.7 & $12.36 \mathrm{~h}$ & 18 \\
\hline${ }^{28} \mathrm{Al}(\beta-) \gamma \rightarrow{ }^{28} \mathrm{Si}$ & 1778.969 & $2.2414 \mathrm{~min}$ & 100 \\
\hline${ }^{56} \mathrm{Mn}(\beta+) \gamma \gamma_{2} \rightarrow{ }^{56} \mathrm{Fe}$ & 1810.726 & $2.578 \mathrm{~h}$ & 26.9 \\
\hline${ }^{56} \mathrm{Mn}(\beta+) \gamma \gamma_{1} \rightarrow{ }^{56} \mathrm{Fe}$ & 2113.123 & $2.578 \mathrm{~h}$ & 14.3 \\
\hline${ }^{24} \mathrm{Na}(\beta-) \gamma{ }_{1} \rightarrow{ }^{24} \mathrm{Mg}$ & 2754.007 & $14.959 \mathrm{~h}$ & 100 \\
\hline
\end{tabular}




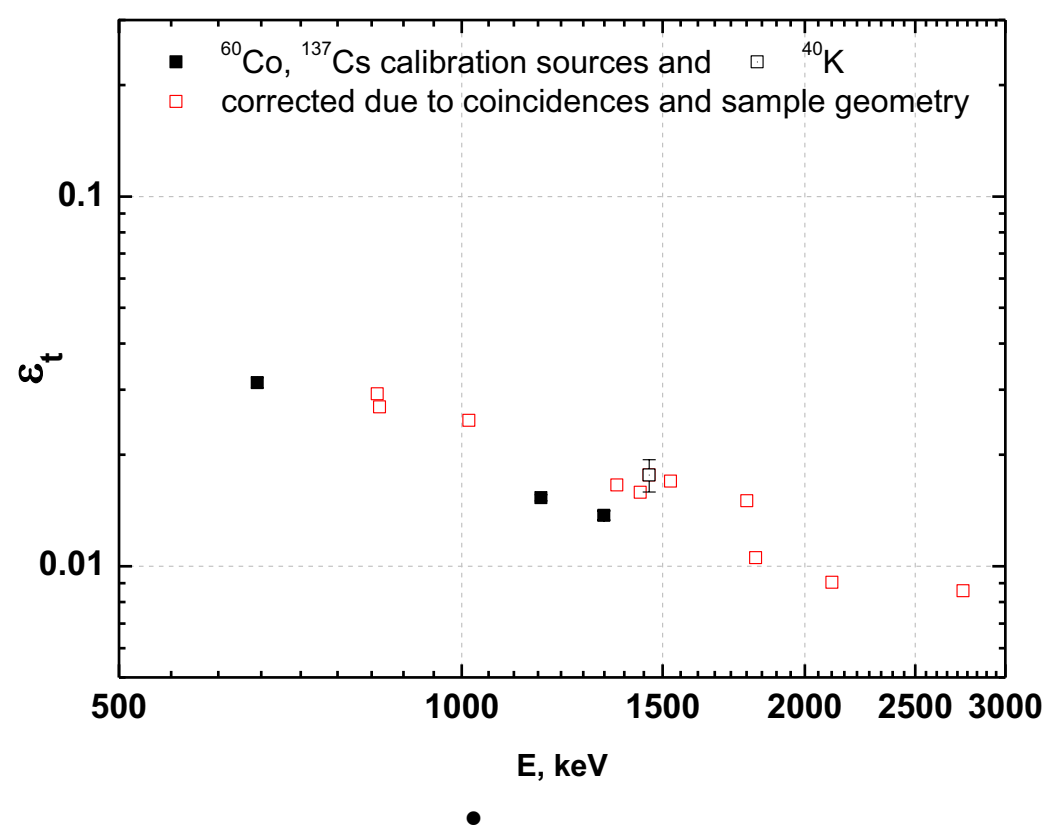

Figure 3. HPGe detector registration efficiency factors for each of the neutron activation products (see also Table I for details).

\section{EXPERIMENTAL MEASUREMENTS AND DOSE RATE DETERMINATION}

Neutron flux was experimentally evaluated by NAA. Reaction rate of activated nuclide generation have been determined from its measured gamma activity. The NAA experimental results were compared with the numerical simulation using MCNP code.

Chemical elements in selected samples were selected considering interactions with neutrons over all ranges of neutron energy distribution, for example : Al - 14.95g metal sample of pure Al was irradiated for fast neutron flux characterization. Representative spectrum of activated Al sample in the central channel is presented in Fig. 4. $\mathrm{V}_{2} \mathrm{O}_{5}+\mathrm{KNO}_{3}(\mathrm{~m}=0.57 \mathrm{~g}+6.6 \mathrm{~g})$, $\mathrm{MnO}_{2}+\mathrm{KNO}_{3}(\mathrm{~m}=0.22 \mathrm{~g}+6.07 \mathrm{~g})$ and $\mathrm{Na}_{2} \mathrm{CO}_{3}+\mathrm{KNO}_{3}(\mathrm{~m}=3.08 \mathrm{~g}+3.08 \mathrm{~g})$ samples in form of powder in plastic Petri dish were used For thermal neutron flux treatment.

A comparison of the reactions rates after activation of the selected samples in the central chanel of the Pu-Be neutron source and corresponding MCNP simulations is presented Table II. Experimentally measured reaction rates are in satisfactory agreement with modeling (MCNP6) reaction rates for thermal neurons and at higher irradiation position $(\mathrm{h}=12 \mathrm{~cm})$ from the neutron source. For fast neutron reaction rates obtained closer to the neutron source $(\mathrm{h}=0)$ the numerical simulations gives higher NAA results (coefficient of 1.2), which means that NAA experiments interact with specimens with a correspondingly lower neutron flux than that calculated by simulations. This could be caused by inaccuracies in the model - mismatches between geometry and real parameters described in the model, inaccuracies in material composition, and so on. Corrected neutron flux is $3.73 \cdot 10^{7} \mathrm{n} / \mathrm{s}$ for all neutron sources. The total neutron flux of $1.15 \cdot 10^{6} \mathrm{n} \cdot \mathrm{s}^{-1} \mathrm{~cm}^{-2}$ is obtained at the dedicated irradiation position of the sample in the central channel. The similar situation was obtained in the experimental channels V1 and V2 - data have shown that the calculated activity for the vanadium and manganese samples is slightly higher than that obtained from the simulations but for the aluminum sample, the simulated activity is slightly higher. 


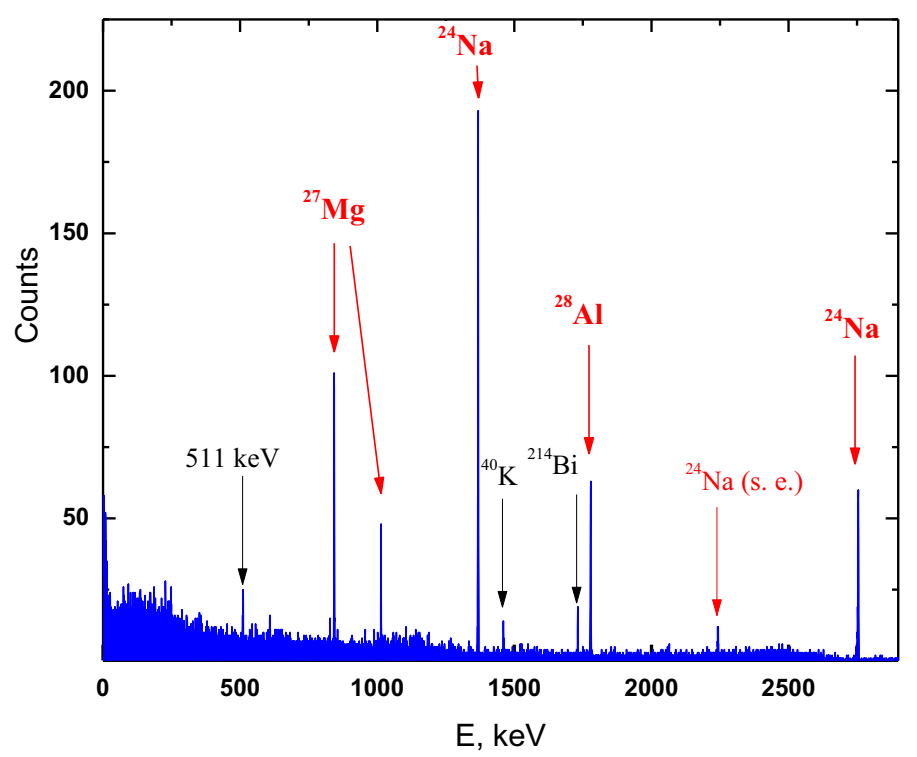

Figure 4. Energy dependent gamma ray spectrum of Al sample activated in the Central channel of the $\mathrm{Pu}-\mathrm{Be}$ neutron sources. Al sample measurement time is $2477 \mathrm{~s}$.

Table II. The comparison of modeled and experimentally estimated reaction rates $(\mathrm{R})$ of the neutron activation in the samples in the Central channel of the neutron storage device

\begin{tabular}{|c|c|c|}
\hline Sample /reaction & $\mathrm{h}, \mathrm{cm}$ & $\mathrm{R}(\mathrm{MCNP}) / \mathrm{R}(\exp )$ \\
\hline \multirow{3}{*}{ 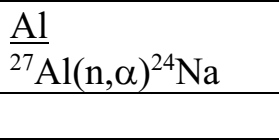 } & 0 & 1.22 \\
\hline & 12 & 0.95 \\
\hline & Ratio $\mathrm{h}_{0} / \mathrm{h}_{12 \mathrm{~cm}}$ & 1.29 \\
\hline \multirow{3}{*}{$\frac{\mathrm{Al}}{{ }^{27} \mathrm{Al}(\mathrm{n}, \mathrm{p}){ }^{27} \mathrm{Mg}}$} & 0 & 1.21 \\
\hline & 12 & 1.07 \\
\hline & Ratio $\mathrm{h}_{0} / \mathrm{h}_{12 \mathrm{~cm}}$ & 1.13 \\
\hline \multirow{3}{*}{ 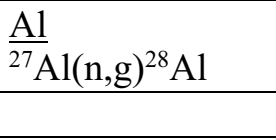 } & 0 & 0.91 \\
\hline & 12 & 0.89 \\
\hline & Ratio $\mathrm{h}_{0} / \mathrm{h}_{12 \mathrm{~cm}}$ & 1.01 \\
\hline \multirow{3}{*}{$\frac{\mathrm{V}_{2} \mathrm{O}_{5}+\mathrm{KNO}_{3}}{{ }^{51} \mathrm{~V}(\mathrm{n}, \gamma)^{52} \mathrm{~V}}$} & 0 & 1.01 \\
\hline & 12 & 0.95 \\
\hline & Ratio $\mathrm{h}_{0} / \mathrm{h}_{12 \mathrm{~cm}}$ & 1.06 \\
\hline \multirow{3}{*}{$\frac{\mathrm{MnO}_{2}}{{ }^{55} \mathrm{Mn}(\mathrm{n}, \gamma)^{56} \mathrm{MnO}}$} & 0 & 1.11 \\
\hline & 12 & 1.11 \\
\hline & Ratio $\mathrm{h}_{0} / \mathrm{h}_{12 \mathrm{~cm}}$ & 1.01 \\
\hline \multirow{3}{*}{$\frac{\mathrm{MnO}_{2}}{{ }^{41} \mathrm{~K}\left(\mathrm{n}, \gamma \mathrm{KNO}_{3}\right.}$} & 0 & 1.04 \\
\hline & 12 & 0.93 \\
\hline & Ratio $\mathrm{h}_{0} / \mathrm{h}_{12 \mathrm{~cm}}$ & 1.12 \\
\hline \multirow{3}{*}{$\frac{\mathrm{Na}_{2} \mathrm{CO}_{3}+\mathrm{KNO}_{3}}{{ }^{23} \mathrm{Na}(\mathrm{n}, \gamma){ }^{24} \mathrm{Na}}$} & 0 & 1.03 \\
\hline & 12 & 1.02 \\
\hline & Ratio $\mathrm{h}_{0} / \mathrm{h}_{12 \mathrm{~cm}}$ & 1.02 \\
\hline \multirow{2}{*}{$\frac{\mathrm{Na}_{2} \mathrm{CO}_{3}+\mathrm{KNO}_{3}}{{ }^{41} \mathrm{~K}(\mathrm{n}, \gamma){ }^{42} \mathrm{~K}}$} & 0 & 0.95 \\
\hline & 12 & 0.98 \\
\hline & Ratio $\mathrm{h}_{0} / \mathrm{h}_{12 \mathrm{~cm}}$ & 0.97 \\
\hline
\end{tabular}


The Properly modeled neutron flux at the sample irradiation position allows a reliable estimation of the neutron radiation dose rate to the sample. Corrections are used in subsequent calculations to evaluate dose rate (Table III). D is calculated with MCNP6 using D(E) ICRP74 standard [7]. The dose rate for the sample in of the central channel is of order of $55 \mathrm{mSv} / \mathrm{h}, \mathrm{V} 1$ channel $30 \mathrm{mSv} / \mathrm{h}$, V2channel $-19 \mathrm{mSv} / \mathrm{h}$.

Table III. Calculated neutron flux and dose rate estimation for sample at the irradiation positions $(\mathrm{h}=0)$ at Central, Vertical I and Vertical II channels of the neutron storage device.

\begin{tabular}{|c|c|c|c|c|c|}
\hline Channel & $\phi\left(\mathrm{n}^{-1} \mathrm{~s}^{-2}\right)$ & $\mathrm{n}_{\text {thermal }}$ & $\mathrm{n}_{\text {epithermal }}$ & $\mathrm{n}_{\text {fast }}$ & Dose rate, $\mathrm{mSv} / \mathrm{h}$ \\
\hline $\mathrm{C}$ & $1.15 \times 10^{6}$ & 19 & 28 & 53 & $55.1 \pm 0.5$ \\
\hline $\mathrm{V} 1$ & $1.19 \times 10^{6}$ & 37 & 26 & 37 & $30.1 \pm 0.7$ \\
\hline $\mathrm{V} 2$ & $3.91 \times 10^{5}$ & 39 & 25 & 35 & $13.7 \pm 0.6$ \\
\hline
\end{tabular}

\section{CONCLUSIONS}

The absolute neutron intensity at dedicated irradiation points as well as neutron and gamma dose rates are obtained. Experimentally measured reaction rates are in $2 \sigma$ range agreement with modelling (MCNP6) reaction rates. Corrected neutron intensity is $3.73 \cdot 10^{7} \mathrm{n} / \mathrm{s}$ and constitute $83 \%$ of the neutron documented neutron source intensity. The dose rate for the sample in the dedicated irradiation position of the central channel is of order of $55.1 \pm 0.5 \mathrm{mSv} / \mathrm{h}, \mathrm{V} 1$ channel $-30.1 \pm 0.7 \mathrm{mSv} / \mathrm{h}, \mathrm{V} 2$ channel $13.7 \pm 0.6 \mathrm{mSv} / \mathrm{h}$.

\section{REFERENCES}

1. L. Hamidatou, H. Slamene, T. Akhal and B. Zouranen, Concepts, Instrumentation and Techniques of Neutron Activation Analysis, Imaging and Radioanalytical Techniques in Interdisciplinary Research Fundamentals and Cutting Edge Applications, Ch. 6, 142, 155 (2013).

2. D.B. Pelowitz, MCNP6 User's Manual, Version 1.0, Report LA-CP-13-00634, Los Alamos National Laboratory, New Mexico (2013).

3. M.B. Chadwick et al., "ENDF/B-VII.0: Next generation evaluated nuclear data library for nuclear science and technology", Nucl. Data Sheets 107(2006)2931.

4. IAEA-TECDOC-564 (1990) Practical aspects of operating a neutron activation analysis laboratory, IAEA, Vienna, ISSN 1011-4289

5. S.-T. Park and N. H. Jang, "Estimation and Calibration of Thermal Neutron Flux for Neutron Activation Analysis," Bull. Korean Chem. Soc., 27, no. 12, pp. 2061-2063 (2006)

6. A. Gudelis, V. Remeikis, A. Plukis, D. Lukauskas, Efficiency calibration of HPGe detectors for measuring environmental samples. Envir. and Chem. Phys., 22, no. 3-4,pp. 117-125 (2000).

7. C.H. Clement et al., Annals of the ICRP 41, Sup 1 ISSN 0146-6453 (2012). 